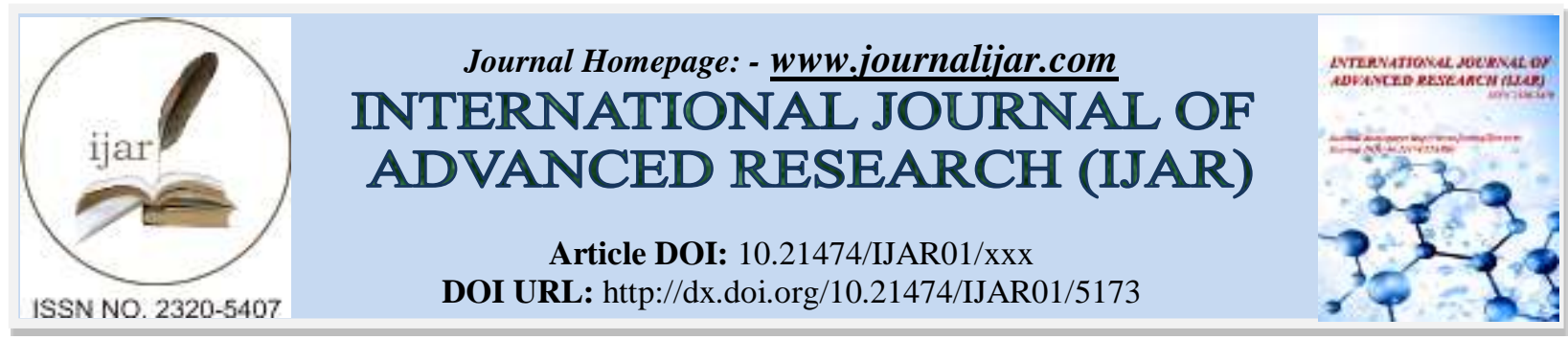

RESEARCH ARTICLE

\title{
THICKENED LIQUIDS: ARE THEY SCIENTIFICALLY ACCURATE?
}

\author{
Lindsey B. Bantley ${ }^{1}$, BS, M.A. CF-SLP, Andrea J. Wortkoetter ${ }^{1}$, BS, M.A. CF-SLP, Mary J. Ewing ${ }^{1}$, M.A., \\ CCC-SLP, CLC, BCS-S and "Ranjith Wijesinghe ${ }^{2}$. \\ 1. Department of Speech-Language Pathology, Ball State University, Muncie, IN, USA. \\ 2. Department of Physics and Astronomy, Ball State University, Muncie, IN, USA.
}

\section{Manuscript Info}

Manuscript History

Received: 14 June 2017

Final Accepted: 16 July 2017

Published: August 2017

Key words:-

Deglutition, deglutition disorders, dysphagia, National Dysphagia Diet, thickened liquids, viscosity

\begin{abstract}
The treatment of dysphagia is hindered by the use of various recipes used for thickening liquids in swallowing and feeding therapy. At present, there is limited standardized methodology for determining the viscosity of liquid levels and dietary modifications. During experiments conducted in an Immersive Learning course at Ball State University, measurements were obtained to analyze the viscosities of thickened liquids. These measurements were compared to Varibar Barium to determine the comparison between Varibar and prescribed thickened liquids. Results indicated there were no commercial thickeners that were consistent, fell within the NDD level, and most closely compared with Varibar Barium across all trials and thickness levels, consequently demonstrating the variability between thickeners, mixing methods, and persons mixing the liquid.
\end{abstract}

Copy Right, IJAR, 2017,. All rights reserved.

\section{Introduction:-}

Researchers have suggested that there may not be a consistent, reliable mixing procedure when thickening liquids for the treatment of dysphagia [1,2]. Dysphagia can be defined as uncoordinated (i.e. decreased bolus control) or difficulty swallowing due to impaired muscles or nerves of the swallowing mechanism, which can result in dehydration, malnutrition, aspiration pneumonia, and asphyxiation [2,3]. Dysphagia or deglutition disorders, can be associated with medical etiologies such as oral and esophageal cancers, stroke, cerebral palsy, myasthenia gravis, Parkinson's disease and amyotrophic lateral sclerosis (ALS) to name a few [1-3]. Populations affected by dysphagia are typically elderly, however, dysphagia can be seen in younger adults and pediatric patients alike. Researchers reported one in nine elderly adults (i.e. 69-98 years of age) experience dysphagia symptoms [4]. Furthermore, 52.7 $\%$ of patients in nursing homes are diagnosed with dysphagia [3].

Treatment of dysphagia may be categorized as rehabilitative or compensatory; where rehabilitative refers to improving the functional integrity of the swallowing mechanism (e.g. Mendelsohn Maneuver and oral exercises to improve lip and tongue functioning) and compensatory refers to consuming food and drink without improving the functional integrity of the swallowing mechanism (e.g. head postures, swallowing techniques, diet modification, thickening liquids, environmental modifications, and prosthetics) [3]. Bolus control can be further explained by researchers Cichero et al., "regular (i.e. thin) fluids require finely tuned coordination and timing between a multitude of muscles and nerves, while thick liquids tend to flow more slowly allowing better control of the bolus," hence the utilization of diet modifications and thickened liquids for the treatment of dysphagia [2]. To attempt standardization of diet modifications, dieticians, SLPs, and a food scientist developed the National Dysphagia Diet (NDD). The 
NDD consists of food (i.e. Level 1: Pureed, Level 2: Mechanical Altered, Level 3: Advanced, and Regular) and liquid (i.e. Thin, Nectar-like, Honey-like, and Spoon-thick) modification levels, which remain in practice today [5].

Thickened liquids are often prescribed to patients with dysphagia who have poor bolus control during deglutition (i.e. the act of swallowing) in the oral and/or pharyngeal phases. In a 2005 survey, of the 145 SLP respondents, $84.6 \%$ of SLPs prescribed thickened liquids [6]. To determine the frequency at which SLPs prescribe thickened liquids, it was reported that one-fourth to three fourths of the caseload of an SLP in a medical setting with patients who have dysphagia were on liquid modifications [7]. Furthermore, in a survey of SLPs and Registered Dietitians (RD), $85 \%$ believed the use of texture-modified diets was beneficial for patients. In this same survey, $84 \%$ of respondents supported the use of the NDD, while 73\% of respondents believed the NDD to be evidence based [8]. Of the respondents who disagreed with the NDD, the majority were SLPs. It is important to note SLPs are not the only specialty assisting patients who have dysphagia. As indicated above, RDs utilize diet modification to ensure adequate nutrition of the patient [9]. Specifically, RDs select a thickener type and brand for their facility; SLPs have limited involvement with this aspect of diet modification [7].

Many patients with dysphagia are prescribed thickened liquids by Doctors of Medicine (MDs), dieticians, registered nurses (RNs), SLPs, and other professionals as a form of compensatory treatment; however, there is variability and a lack of standardization of the preparation of thickened liquids [1-3]. A recent study performed by Payne et al. shows a statistically significant discrepancy between the thickened liquids prepared by hospital SLPs when compared to thickened liquids prepared in the laboratory, while both groups followed the same instructions [10]. Therefore, demonstrating variability and a lack of standardization among the preparation of thickened liquids. Similar results were concluded in previous studies by researchers Glassburn and Deem in 1998 [11].

The purpose of this study is to contribute to the scarce body of current research regarding the assessment and treatment of dysphagia, while bridging the gap between the liquids used during assessment and the liquids prescribed for treatment. It is imperative for packaging and mixing methods of thickened liquids to be consistent and easily replicable in order for patients, caregivers, nurses, and SLPs to prepare thickened liquids consistent with the thickness level the patient was assessed at during the clinical and instrumental evaluation. "If adjustment of fluid thickness has a reliable and demonstrated impact on improved health outcomes, then the exact thickness of the liquids needs to be identified, described and reported in such a way that it can be reliably reproduced," [2]. Without the consistency and reliability of thickened liquids, patients are at an increased risk for health complications such as aspiration.

It is not only important for professionals to easily replicate thickened liquids that fall within the proper viscosity range prescribed, but for patients alike. Glassburn and Deem explain this by stating, "without the ability to reliably reproduce consistencies, patients cannot receive consistent treatment across the continuum from evaluation to daily intake. If SLPs are not consistent within their own mixing attempts, it is even less likely that the consistency judged to be safe for the patient during a videofluoroscopic or bedside evaluation is the same consistency the patient later receives from another SLP or hospital staff' [11]. Ultimately, our goal is to improve assessment and the treatment in order to increase the safety and well being of patients with dysphagia.

\section{Procedure:-}

Viscosity refers to the thickness of a liquid, or a liquid's resistance to flow, and is measured in centipoise (cP). A viscometer is the instrument used to measure the viscosity of liquids. A spindle is the tool attached to the viscometer, which spins in the beaker of liquid and attains the data. The viscometers used in this study were Brookfield DV3T and Brookfield DV2T viscometers. The viscometers were calibrated when they were constructed, before they were shipped to Ball State University (i.e. Brookfield DV3T was calibrated in 2016 and Brookfield DV2T was calibrated in 2015). In the current study, viscosity levels used for experiments where the liquid viscosity levels identified by the NDD (i.e. Thin $=0-50 \mathrm{cP}$, Nectar $=51-350 \mathrm{cP}$, Honey $=351-1750 \mathrm{cP}$, Pudding $=>1751 \mathrm{cP}$ ). Authors chose to utilize the NDD during the study, due to it being the most widely used thickened-liquid diet prescribed by speech language pathologists for patients with dysphagia. When measuring the viscosity of thickened liquids, one must determine at what shear rate the liquid should be measured. Viscosity is defined as shear stress divides by shear rate. Shear rate refers to the rate at which the layers of a liquid slide against one another when stress is placed upon the liquid. If the viscosity of a fluid remains constant, a higher shear rate means higher shear stress as well. However, if we consider a patient with a lower shear stress, which is the case for them since their swallowing ability is weaker, that means they swallow slowly since shear rate is also lower. The current study used 
a shear rate of 30 1/s for the ease of comparison to Varibar Barium.

There are two common types of thickeners used in the treatment of dysphagia: starch-based and gum-based. Starchbased thickeners come in powder form, thicken over time, and are typically less costly. Starch-based thickeners used in the current study include Thick-It and Thick \& Easy. Gum-based thickeners come in powder and gel form, typically have a more stable viscosity, and generally are more expensive than starch-based thickeners. Gum-based thickeners used in the current study include SimplyThick, Thik \& Clear, and Thicken Up Clear. There are also prethickened liquids that can be purchased. The prethickened brands used in the current study include GFS, Hormel Thick \& Easy, and Thick-It.

\section{Methods:-}

Directions included on the packaging of each brand of thickener were followed in order to prepare the thickened liquids. Instructions on SimplyThick packaging stated liquids should be shaken. The remaining two gum-based thickeners, Thik \& Clear and Thicken Up Clear, were mixed with a fork. Throughout preparation for each sample, liquids were shaken at 30-second time intervals to ensure consistency of preparation. In the instance that there were still visible masses of thickener, the liquids were shaken for an additional 30 seconds as needed. All samples mixed with a fork were stirred vigorously for one minute. Regardless of vigorousness, the samples had visible masses of unmixed gel and air bubbles throughout the sample. All samples of gum-based thickeners sat for 5 minutes prior to being tested. Thick \& Easy specified allowing liquids to stand for one to four minutes; each sample stood for two minutes in the current experiment. Each brand of thickener and thickness level were tested at room temperature and cold, where room temperature was $25^{\circ} \mathrm{C}$ and cold was $9^{\circ} \mathrm{C}$. Cold samples were stored in the refrigerator overnight, and room temperature samples were heated using a heat bath. For the samples that tested the viscosity of thickened coffee, the coffee was made, cooled to $57.8^{\circ} \mathrm{C}$, then added the specific commercial thickener being tested. For prethickened samples, the prethickened liquid was opened, and then added to a beaker for testing. All trials conducted were completed within forty-five minutes.

\section{Results:-}

All samples were mixed via package instructions, 10 consecutive trials were run on each sample, and then data was recorded. Values reported were the average viscosity of the ten trials. The results below are separated by viscosity and thickener type as indicated by the figure title.

Figure 1: Nectar-Thick Gum-Based Thickeners Compared to Varibar Nectar Barium. Varibar Nectar tested with an average viscosity of $88.5 \mathrm{cP}$. This is on the low range of the nectar-thick liquids in the NDD, however all trials fell within nectar-thick viscosity range $(51-350 \mathrm{cP})$. All trials fell within 2 points of viscosity of another. SimplyThick water room temperature tested with an average viscosity of $169.2 \mathrm{cP}$. This is most closely compared with the average viscosity of Varibar Nectar, varying by $80.7 \mathrm{cP}$. All trials fell within NDD nectar-thick range. SimplyThick water cold tested with an average viscosity of $225.6 \mathrm{cP}$. This most closely compared with the average of the NDD nectar-thick range, varying by $25.6 \mathrm{cP}$. All trials fell within NDD nectar-thick range. Thik \& Clear water room temperature tested with an average viscosity of $472 \mathrm{cP}$. This exceeds the maximum viscosity of NDD nectar-thick liquids by $122 \mathrm{cP}$. All ten trials fell above NDD nectar-thick range, but they did vary the least (range of $12.8 \mathrm{cP}$ ). Thik \& Clear water cold tested with an average viscosity of $579.5 \mathrm{cP}$. This exceeds the maximum viscosity of the nectar-thick range by $226.5 \mathrm{cP}$. All trials exceeded the desired viscosity and gradually decreased in viscosity throughout the 10 trials. Thicken Up Clear water room temperature tested with an average viscosity of $328 \mathrm{cP}$. This is close to the highest acceptable viscosity for nectar-thick liquids, but does not exceed it. Thicken Up Clear gradually increased in viscosity throughout testing resulting in eight trials that surpassed the maximum $350 \mathrm{cP}$ of nectar-thick NDD liquids. Thicken Up Clear water cold tested with an average viscosity of $329.2 \mathrm{cP}$. Six of the ten trials exceeded the maximum nectar-thick NDD viscosity range. In summary, for cold and room temperature water, SimplyThick most closely compared with the average viscosity of the Varibar Nectar, stayed within the NDD level for nectar-thick liquids, and was the most consistent in regards to thickness over time.

Figure 2: Nectar-Thick Starch-Based Thickeners Compared to Varibar Nectar Barium. Thick-It water room temperature tested with an average viscosity $136.4 \mathrm{cP}$. All trials fell within NDD nectar-thick range. This thickener gradually increased in viscosity throughout testing, varying $55.2 \mathrm{cP}$ between the first trial and tenth trial, after 30 minutes. Thick-It water room temperature most closely compared with the average of the NDD nectar-thick range, varying from the midpoint by $64.1 \mathrm{cP}$. Thick-It water cold tested with an average viscosity of $282.8 \mathrm{cP}$. All trials fell within NDD nectar-thick range, but where on the high end; all trials were over $230 \mathrm{cP}$. Thick-It water cold tested 
with the most difference between lowest and highest trials, varying by $101.6 \mathrm{cP}$. Thick \& Easy water room temperature tested with an average viscosity of $88.8 \mathrm{cP}$. This most closely compared with the average viscosity of Varibar Nectar varying by $0.275 \mathrm{cP}$. All trials were within nectar-thick range, but gradually increased in viscosity throughout testing beginning with $62.4 \mathrm{cP}$ and ending with $115.2 \mathrm{cP}$ after 31 minutes of testing. Thick \& Easy water cold tested with an average viscosity of $110.4 \mathrm{cP}$. This was the smallest range between the lowest and highest viscosities varying by $33.6 \mathrm{cP}$. All trials fell within NDD range. The viscosity increased gradually, and by the middle of testing began to decrease. In summary, for room temperature water, Thick-It most closely compared with the average viscosity of the Varibar Nectar. However, Thick \& Easy stayed most consistent in regards to thickness over time, however, all thickeners gradually thickened over time. Both Thick-It and Thick \& Easy remained within the NDD level for nectar-thick liquids.

Figure 3: Nectar-Thick Prethickened Room Temperature Liquids Compared to Varibar Nectar Barium. GFS Lemon Water room temperature tested with an average viscosity of $471.6 \mathrm{cP}, 121.6 \mathrm{cP}$ above the maximum acceptable viscosity for NDD nectar-thick liquids. All ten trials exceeded the maximum for nectar-thick liquids. Thickness gradually decreased throughout testing. GFS Apple Juice room temperature tested with an average viscosity of 480.8 $\mathrm{cP}, 130.8 \mathrm{cP}$ higher than the maximum viscosity for NDD nectar-thick liquids. All ten trials exceed the NDD range and gradually decreased in viscosity throughout testing. Thick-It Apple Juice room temperature tested with an average viscosity of $414 \mathrm{cP}, 64 \mathrm{cP}$ higher than the maximum viscosity for NDD nectar-thick liquids. All trials exceeded the maximum viscosity for NDD liquids and gradually decreased in viscosity throughout testing. Thick-It Water room temperature tested with an average viscosity of $137.5 \mathrm{cP}$. This most closely compared with average of NDD range varying by $63 \mathrm{cP}$. This thickener also had the smallest range between lowest and highest viscosity trials varying by $2.8 \mathrm{cP}$. Therefore it maintained the most consistent viscosity throughout testing compared to all prethickened nectar-thick room temperature liquids tested. All trials fell within NDD nectar range and gradually decreased in viscosity throughout testing. Hormel Thick \& Easy Orange Juice room temperature tested with an average viscosity of $137.1 \mathrm{cP}$. This most closely compared with the average viscosity of Varibar Nectar varying by $48.5 \mathrm{cP}$. All trials fell within NDD nectar range and gradually decreased in viscosity throughout testing. Hormel Thick \& Easy Apple Juice room temperature tested with an average viscosity of $942.2 \mathrm{cP}, 592.2 \mathrm{cP}$ higher than the maximum viscosity for NDD nectar-thick liquids. All trials exceeded the maximum viscosity for NDD liquids and gradually decreased in viscosity throughout testing. Hormel Thick \& Easy HydroLyte Water room temperature tested with an average viscosity of $382.8 \mathrm{cP}, 32.8 \mathrm{cP}$ higher than the maximum viscosity for NDD nectar-thick liquids. All trials exceeded the maximum viscosity for NDD liquids and gradually increased in viscosity throughout testing. In summary, the majority of the prethickened nectar-thick liquids decreased in viscosity throughout testing (i.e. over a 30-minute period) and had all ten trials exceed the maximum viscosity for NDD nectar-thick liquids. Thick-It water at room temperature and Thick \& Easy Orange Juice at room temperature were the only prethickened liquids, which fell within NDD nectar-thick range. Thick-It Water at room temperature remained most consistent in regards to thickness over time. Thick \& Easy Orange Juice at room temperature most closely compared with the average viscosity of Varibar Nectar.

Figure 4: Nectar-Thick Prethickened Cold Liquids Compared to Varibar Nectar Barium. GFS Lemon Water cold tested with an average viscosity of $835.2 \mathrm{cP}, 485.2 \mathrm{cP}$ higher than the maximum viscosity for NDD nectar-thick liquids. All trials exceeded the maximum viscosity for NDD liquids and gradually decreased in viscosity throughout testing. GFS Apple Juice cold tested with an average viscosity of $212.8 \mathrm{cP}$. This most closely compared with the average of NDD nectar-thick range. All trials fell within NDD nectar range and gradually decreased in viscosity throughout testing. Thick-It Apple Juice cold tested with an average viscosity of $432 \mathrm{cP}, 82 \mathrm{cP}$ higher than the maximum viscosity for NDD nectar-thick liquids. Trials maintained a consistent viscosity throughout testing varying by $6.4 \mathrm{cP}$ between the highest and lowest viscosity. All trials exceeded the maximum viscosity for NDD liquids. Thick-It Water cold tested with an average viscosity of $142.7 \mathrm{cP}$. This most closely compared to the Varibar Barium average differing by $54.2 \mathrm{cP}$. This also maintained the most consistent viscosity throughout testing of the prethickened nectar-thick cold liquids because of the smallest range variance of $2.3 \mathrm{cP}$. Hormel Thick \& Easy Orange Juice cold tested with an average viscosity of $185.4 \mathrm{cP}$. All trials fell within NDD nectar range and gradually decreased in viscosity throughout testing. Hormel Thick \& Easy Milk cold tested with an average viscosity of 1884 $\mathrm{cP}, 1534 \mathrm{cP}$ higher than the maximum viscosity for NDD nectar-thick liquids. All trials exceeded the maximum viscosity for NDD liquids and gradually decreased in viscosity throughout testing. Hormel Thick \& Easy Apple Juice cold tested with an average viscosity of $1016.4 \mathrm{cP}, 666.4 \mathrm{cP}$ higher than the maximum viscosity for NDD nectar-thick liquids. All trials exceeded the maximum viscosity for NDD liquids and gradually decreased in viscosity throughout testing. Hormel Thick \& Easy HydroLyte Water cold tested with an average viscosity of 
$1021.1 \mathrm{cP}, 671.1 \mathrm{cP}$ higher than the maximum viscosity for NDD nectar-thick liquids. All trials exceeded the maximum viscosity for NDD liquids and gradually decreased in viscosity throughout testing.

In summary, a majority of the prethickened nectar-thick liquids decreased in viscosity throughout testing (i.e. over a 30-minute period) and had all ten trials exceed the maximum viscosity for NDD nectar-thick liquids. Thick-It Water cold temperature most closely compared with the average viscosity of the Varibar Nectar, stayed within the NDD level for nectar-thick liquids, and stayed most consistent in regards to thickness over time.

Figure 5: Nectar-Thick Coffee Compared to Varibar Nectar Barium. Thick-It mixed with hot coffee tested at average viscosity of $68.5 \mathrm{cP}$, which was $20.0 \mathrm{cP}$ lower than the average viscosity of Varibar Nectar. Nine of the ten trials were within range of nectar-thick liquids, but were on the lower end. The first trial, two minutes after the coffee was mixed with Thick-It commercial thickener, was not within nectar-thick range, $38.2 \mathrm{cP}$. The coffee gradually thickened over time of the ten trials. The range of thickness varied by $60.6 \mathrm{cP}$. SimplyThick mixed with hot coffee tested with an average viscosity of $105.6 \mathrm{cP}$, varying from the Varibar Nectar average by $17.1 \mathrm{cP}$. All ten trials fell within nectar-thick NDD range and most closely compared with the average viscosity of the NDD range and Varibar Nectar. The thickener did gradually thicken over time, varying $33.2 \mathrm{cP}$ between the lowest and highest viscosity of the 10 trials. In summary, for hot coffee, SimplyThick most closely compared with the average viscosity of the Varibar Nectar, stayed within the NDD level for nectar-thick liquids, and stayed most consistent in regards to thickness over time.

Figure 6: Honey-Thick Gum-Based Thickeners Compared to Varibar Thin Honey Barium. Varibar Thin Honey Barium tested with an average viscosity of $3528 \mathrm{cP}, 1778 \mathrm{cP}$ higher than the maximum viscosity for honey-thick liquids in the NDD. Varibar gradually decreased in viscosity throughout testing. All trials exceeded the NDD honeythick range. SimplyThick water room temperature tested with an average viscosity of $441.2 \mathrm{cP}$. All trials fell within NDD honey-thick range. Trials gradually increased in viscosity throughout testing, $20 \mathrm{cP}$ between the first and last trial. SimplyThick water cold tested with an average viscosity of 451.2. This was the most consistent thickener varying $17.6 \mathrm{cP}$ between the lowest and highest viscosities of the trials. All trials fell within NDD honey-thick range. Thik \& Clear water room temperature tested with an average viscosity of $2314 \mathrm{cP}, 564 \mathrm{cP}$ higher than the maximum viscosity for NDD honey-thick liquids. This thickener most closely compared with Varibar Thin Honey Barium, however, both exceed the maximum viscosity for NDD honey-thick liquids. Trials did not consistently increase or decrease in viscosity throughout testing. Thik \& Clear water cold tested with an average viscosity of $1786 \mathrm{cP}, 36 \mathrm{cP}$ higher than the maximum viscosity for NDD honey-thick liquids. Three of the ten trials exceeded the maximum for NDD honey-thick liquids. This thickener did not maintain consistency throughout testing, varying 740 $\mathrm{cP}$ between the highest and lowest viscosity. Thicken Up Clear water room temperature tested with an average viscosity of $894 \mathrm{cP}$. This most closely compared with the average of the NDD honey-thick range, varying by 156.5 cP. Thicken Up Clear water cold tested with an average viscosity of $1620 \mathrm{cP}$. All trials tested within honey-thick NDD range, but were on the higher end of the range.

In summary, SimplyThick water cold was the most consistent thickener in regards to thickness over time, and all trials fell within NDD honey-thick range. Thik \& Clear water room temperature most closely compared with Varibar Thin Honey, however, both exceed the maximum viscosity for NDD honey-thick liquids. Thicken Up Clear water room temperature most closely compared with the average of the NDD honey-thick range.

Figure 7: Honey-Thick Starch-Based Thickeners Compared to Varibar Thin Honey Barium. Thick-It Water room temperature tested with an average viscosity of $662 \mathrm{cP}$. This most closely compared with the average viscosity of NDD honey-thick range. This thickener most closely compared with Varibar Thin Honey Barium, however, both exceed the maximum viscosity for NDD honey-thick liquids. Thick-It water cold tested with an average viscosity of $558 \mathrm{cP}$. All trials tested within honey-thick NDD range and gradually increased in viscosity throughout testing. Thick \& Easy water room temperature tested with an average viscosity of $554 \mathrm{cP}$. All trials tested within honeythick NDD range and gradually increased in viscosity throughout testing. Thick \& Easy water cold tested with an average viscosity of $644 \mathrm{cP}$. This maintained the most consistent viscosity throughout testing of these starch thickeners varying by $216 \mathrm{cP}$ between the lowest and highest viscosities. All trials tested within honey-thick NDD range and gradually increased in viscosity throughout testing. In summary, all honey-thick starch trials were within NDD range and increased in viscosity over time, regardless of temperature or thickener brand. Thick \& Easy water cold temperature maintained the most consistent viscosity throughout testing.

Figure 8: Honey-Thick Prethickened Room Temperature Liquids Compared to Varibar Thin Honey Barium. GFS 
Lemon Water room temperature tested with an average viscosity of $972 \mathrm{cP}$. This most closely compared with the average of the NDD honey-thick range, varying by $78.5 \mathrm{cP}$. All trials fell within NDD honey range and gradually decreased in viscosity throughout testing. GFS Apple Juice room temperature tested with an average viscosity of $1158 \mathrm{cP}$. All trials tested within the NDD range and gradually decreased in viscosity throughout the testing. Thick-It Apple Juice room temperature tested with an average viscosity of $714.4 \mathrm{cP}$. All trials tested within the NDD range and gradually decreased in viscosity throughout the testing except the last three trials, which increased in viscosity by $0.8 \mathrm{cP}$. Thick-It Water room temperature tested with an average viscosity of $245.4 \mathrm{cP}$. Trials maintained a consistent viscosity throughout testing varying by $2.1 \mathrm{cP}$ between the highest and lowest viscosity. All trials fell within NDD honey range and gradually decreased in viscosity throughout testing except the last three trials, which increased in viscosity by $0.3 \mathrm{cP}$. Hormel Thick \& Easy Orange Juice room temperature tested with an average viscosity of $1836 \mathrm{cP}, 86 \mathrm{cP}$ higher than the maximum viscosity of NDD honey-thick liquids. All trials exceeded the honey-thick NDD range. Hormel Thick \& Easy Apple Juice room temperature tested with an average viscosity of $2120 \mathrm{cP}, 370 \mathrm{cP}$ higher than the maximum viscosity of NDD honey-thick liquids. This thickener most closely compared with Varibar Thin Honey Barium, however, both exceed the maximum viscosity for NDD honey-thick liquids. All trials exceeded the honey-thick NDD range and gradually increased in viscosity throughout testing. Hormel Thick \& Easy HydroLyte Water room temperature tested with an average viscosity of $1672 \mathrm{cP}$ with a gradual decrease in viscosity over time. All trials fell within the NDD range, but tested on the high end of the range.

In summary, a majority of the prethickened honey-thick room temperature liquids had all ten trials exceed the maximum viscosity for NDD honey-thick liquids. Additionally, most prethickened liquids decreased in viscosity throughout testing (i.e. over a 30-minute period), with the exception of Thick-It (variable) and Thick \& Easy HydroLyte (increased). GFS Lemon Water room temperature most closely compared with the average of the NDD honey-thick range. Thick-It Water room temperature maintained the most consistent viscosity throughout testing. Thick \& Easy Apple Juice room temperature most closely compared with Varibar Thin Honey Barium, however, both exceed the maximum viscosity for NDD honey-thick liquids.

Figure 9: Honey-Thick Prethickened Cold Liquids Compared to Varibar Thin Honey Barium. GFS Lemon Water cold tested with an average viscosity of $950 \mathrm{cP}$. This most closely compared with the average of the NDD honeythick range, varying by $100.5 \mathrm{cP}$. All trials fell within the honey-thick NDD range and gradually decreased in viscosity throughout testing. GFS Apple Juice cold tested with an average viscosity of $2126 \mathrm{cP}, 376 \mathrm{cP}$ higher than the maximum viscosity for honey-thick liquids in the NDD. All trials exceeded the honey-thick NDD range and gradually decreased in viscosity throughout testing except between trials one and two. The viscosity for trial one was $2196 \mathrm{cP}$ and $2224 \mathrm{cP}$ for trial two. This increased by $28 \mathrm{cP}$ then proceeded to gradually decrease in viscosity by trial ten. Thick-It Apple Juice cold tested with an average viscosity of $750.8 \mathrm{cP}$. All trials fell within the honey-thick NDD range and gradually decreased in viscosity throughout testing. Thick-It Water cold tested with an average viscosity of $194.6 \mathrm{cP}, 156.4 \mathrm{cP}$ lower than the minimum viscosity for honey-thick liquids in the NDD. Trials maintained a consistent viscosity throughout testing varying by $3.6 \mathrm{cP}$ between the highest and lowest viscosity. All were below the honey-thick NDD range and slightly decreased in viscosity throughout testing. Hormel Thick \& Easy Orange Juice cold tested with an average viscosity of $2002 \mathrm{cP}, 252 \mathrm{cP}$ higher than the maximum viscosity for honey-thick liquids in the NDD. All trials exceeded the NDD honey-thick range and were variable from trial to trial. Hormel Thick \& Easy Milk cold tested with an average viscosity of $2104 \mathrm{cP}, 354 \mathrm{cP}$ higher than the maximum viscosity for honey-thick liquids in the NDD. All trials exceeded the honey-thick NDD range and drastically decreased throughout testing. The difference between the first trial and the tenth trial was a decrease of $624 \mathrm{cP}$ in 30 minutes. Hormel Thick \& Easy Apple Juice cold tested with an average viscosity of $3256 \mathrm{cP}, 1506 \mathrm{cP}$ higher than the maximum viscosity for NDD honey-thick liquids. This thickener most closely compared with Varibar Thin Honey Barium however both exceed the maximum viscosity for NDD honey-thick liquids. All trials exceeded the honey-thick NDD range and drastically decreased throughout testing. The difference between the first trial and the tenth trial was a decrease of $752 \mathrm{cP}$ in 30 minutes. Hormel Thick \& Easy HydroLyte Water cold tested with an average viscosity of $2416 \mathrm{cP}, 666 \mathrm{cP}$ higher than the maximum viscosity for NDD honey-thick liquids. All trials exceeded the honey-thick NDD range and drastically decreased throughout testing. The difference between the first trial and the tenth trial was a decrease of $512 \mathrm{cP}$ in 30 minutes.

In summary, a majority of the prethickened honey-thick, cold temperature liquids had all ten trials exceed the maximum viscosity for NDD honey-thick liquids with the exception of GFS Lemon Water (fell within), Thick-It Apple Juice (fell within) and Thick-It Water (below). Additionally, most prethickened liquids decreased in viscosity 
throughout testing (i.e. over a 30-minute period), with the exception of Thick \& Easy Orange Juice (variable) and Thick-It Water (consistent). Thick-It Water cold remained the most consistent in regards to viscosity over time. Thick \& Easy Apple Juice cold most closely compared with Varibar Thin Honey Barium, however, both exceeded the maximum viscosity for NDD honey-thick liquids. GFS Lemon Water cold most closely compared with the average of the NDD honey-thick range.

Figure 10: Honey-Thick Coffee Compared to Varibar Thin Honey Barium. Thick-It coffee tested with an average viscosity of $139.2 \mathrm{cP}, 211.8 \mathrm{cP}$ lower than the minimum viscosity for NDD honey-thick liquids. No trials tested within honey-thick range. Viscosity gradually increased as the time increased. SimplyThick coffee tested with an average viscosity of $79.2 \mathrm{cP}, 271.8 \mathrm{cP}$ lower than the minimum viscosity for NDD honey-thick liquids. Viscosity gradually increased throughout testing, however, no samples fell within NDD honey-thick range. SimplyThick maintained a more consistent viscosity than Thick-It varying $44 \mathrm{cP}$ rather than $150.4 \mathrm{cP}$. In summary, neither ThickIt or SimplyThick hot coffee measured within NDD honey-thick range; both measured over $200 \mathrm{cP}$ lower than the minimum viscosity of the NDD honey-thick range. SimplyThick maintained a more consistent viscosity throughout testing.

\section{Discussion:-}

Typically, starch-based thickeners proved to have the most inconsistent viscosity, as displayed in Tables 1 and 2 . In addition, their viscosities were inversely correlated to those of Varibar Barium (i.e. liquids thickened with starchbased thickeners increased in viscosity over time, while Varibar Barium decreased in viscosity over time). The viscosities of gum-based thickeners were inversely correlated to those of Varibar Barium. Cold samples of both starch and gum-based thickeners, at all consistencies tested, tended to have a higher viscosity than room temperature samples. Thickened coffee had the most inconsistent viscosity among all thickened liquids included in the study. Prethickened liquids had the most consistent viscosity and were highly correlated to Varibar Barium. Among the prethickened liquids tested, the viscosity of cold samples had higher variations when compared to room temperature samples (i.e. the viscosity of thickened liquids at room temperature were more consistent than those of thickened liquids at a cold temperature). Therefore, according to statistical analysis, prethickened liquids had a more consistent viscosity when compared to both gum-based and starch-based thickeners.

\section{Summary/Conclusion:-}

In conclusion, there were no commercial thickeners that were consistent, fell within the NDD level, and most closely compared with Varibar Barium across all trials and thickness levels, consequently demonstrating the variability between thickeners, mixing methods, and persons mixing the liquid. Therefore, it is imperative to account for all the aforementioned factors when thickening liquids. According to statistical analysis, prethickened liquids have a more consistent viscosity when compared to both the gum-based and the starch-based thickeners. Further standardization of thickeners and barium is recommended to increase consistency and reliability of the assessment and treatment of dysphagia.

\section{Future Directions:-}

Due to much variability in preparation techniques of thickened liquids, standardization between samples proved difficult. Recommendations include: SLPs, hospital staff, and patients should be trained on the preparation of thickened liquids, remember that liquids thickened with starch-based thickeners thicken over time, and consider testing multiple recipes with commercial thickeners and food products. Additional research for standardization needs to be considered (e.g. packaging standards, packaging labels, and testing recipes currently being used). Internal consistency between Varibar Barium of separate lot numbers was variable, which may be due to temperature while shipping, how long the product sat before being shipped, etc. Specifically, Varibar Nectar Barium tested at the beginning of the study tested with an average viscosity of $88.5 \mathrm{cP}$. Varibar Nectar Barium tested at the end of this study, from a separate lot number, tested with an average viscosity of $296.4 \mathrm{cP}$. Additionally, Varibar Thin Honey Barium tested at the beginning of the study tested with an average viscosity of $3258 \mathrm{cP}$. Varibar Thin Honey Barium tested at the end of this study, from a separate lot number, tested with an average viscosity of 1692.8 cP. A replication of this study may not produce the same results, further proving a need for standardization of thickened liquids across assessment and treatment of dysphagia.

\section{Acknowledgments:-}

This research project was funded by a Ball State University Immersive Learning grant. A special thank you to the 
community partners involved in this project: Bethel Pointe Health and Rehabilitation, Catherine Seitz, M.A., CCCSLP, BCS-S, and Molly Jones at St. Vincent Health Systems.

Table 1:- Statistical analysis of nectar-thick liquids

\begin{tabular}{|c|c|c|c|c|c|}
\hline \multicolumn{6}{|c|}{ Nectar-Thick Liquids Statistically Compared to Varibar Nectar Barium } \\
\hline Type of Liquid & Trials & $\begin{array}{l}\text { Averaged } \\
\text { Viscosity } \\
\text { (cP) }\end{array}$ & $\mathrm{STD}(\mathrm{cP})^{\mathrm{a}}$ & $\begin{array}{l}\text { Percentage } \\
\text { of } \\
\text { Variance } \\
\text { (STD/ } \\
\text { Averaged } \\
\text { Viscosity) }\end{array}$ & $\begin{array}{l}\text { Correlation } \\
\text { Coefficient }\end{array}$ \\
\hline Varibar Nectar Barium & 10 & 88.53 & 0.66 & $0.74 \%$ & \\
\hline \multicolumn{6}{|l|}{ Prethickened } \\
\hline GFS Lemon Water (Room Temperature) & 10 & 471.60 & 8.72 & $1.85 \%$ & 0.95 \\
\hline GFS Apple Juice (Room Temperature) & 10 & 480.80 & 22.29 & $4.64 \%$ & 0.9 \\
\hline Thick-It Apple Juice (Room Temperature) & 10 & 414.00 & 13.65 & $3.30 \%$ & 0.99 \\
\hline Thick-It Water (Room Temperature) & 10 & 137.50 & 0.84 & $0.61 \%$ & 0.99 \\
\hline $\begin{array}{l}\begin{array}{l}\text { Hormel Thick \& } \\
\text { Temperature) }\end{array}\end{array}$ & 10 & 137.05 & 3.78 & $2.76 \%$ & 0.85 \\
\hline $\begin{array}{l}\begin{array}{l}\text { Hormel Thick } \\
\text { Temperature) }\end{array} \\
\end{array}$ & 10 & 942.20 & 13.77 & $1.46 \%$ & 0.91 \\
\hline $\begin{array}{l}\text { Hormel Thick \& Easy HydroLyte Water (Room } \\
\text { Temperature) }\end{array}$ & 10 & 382.85 & 8.97 & $2.34 \%$ & 0.96 \\
\hline GFS Lemon Water (Cold) & 10 & 835.25 & 27.31 & $3.27 \%$ & -0.95 \\
\hline GFS Apple Juice (Cold) & 10 & 212.80 & 8.31 & $3.90 \%$ & 0.71 \\
\hline Thick-It Apple Juice (Cold) & 10 & 432.00 & 1.77 & $0.41 \%$ & -0.2 \\
\hline Thick-It Water (Cold) & 10 & 142.75 & 0.78 & $0.55 \%$ & 0.77 \\
\hline Hormel Thick \& Easy Orange Juice (Cold) & 10 & 185.40 & 6.36 & $3.43 \%$ & 0.58 \\
\hline Hormel Thick \& Easy Milk (Cold) & 10 & 1884.00 & 100.63 & $5.34 \%$ & 0.9 \\
\hline Hormel Thick \& Easy Apple Juice (Cold) & 10 & 1016.45 & 77.07 & $7.58 \%$ & 0.98 \\
\hline Hormel Thick \& Easy HydroLyte Water (Cold) & 10 & 1021.05 & 63.1 & $6.18 \%$ & 0.98 \\
\hline \multicolumn{6}{|l|}{ Gum-Based Thickeners } \\
\hline SimplyThick Water (Room Temperature) & 10 & 169.20 & 6.26 & $3.70 \%$ & -0.9 \\
\hline Thik \& Clear Water (Room Temperature) & 10 & 472.00 & 3.91 & $0.83 \%$ & -0.95 \\
\hline Thicken Up Clear Water (Room Temperature) & 10 & 328.00 & 17.68 & $5.39 \%$ & -0.98 \\
\hline SimplyThick Water (Cold) & 10 & 225.60 & 4.13 & $1.83 \%$ & -0.99 \\
\hline Thik \& Clear Water (Cold) & 10 & 579.50 & 13.13 & $2.27 \%$ & 0.88 \\
\hline Thicken Up Clear Water (Cold) & 10 & 329.20 & 15.49 & $4.71 \%$ & -0.9 \\
\hline SimplyThick Coffee & 10 & 105.60 & 11.03 & $10.45 \%$ & -0.84 \\
\hline \multicolumn{6}{|l|}{ Starch-Based Thickeners } \\
\hline Thick \& Easy Water (Room Temperature) & 10 & 88.80 & 14.24 & $16.03 \%$ & -0.87 \\
\hline Thick-It Water (Room Temperature) & 10 & 136.40 & 17.34 & $12.71 \%$ & -0.84 \\
\hline Thick-It Water (Cold) & 10 & 282.80 & 28.29 & $10.00 \%$ & -0.95 \\
\hline Thick \& Easy Water (Cold) & 10 & 110.40 & 9.48 & $8.58 \%$ & -0.85 \\
\hline Thick-It Coffee & 10 & 68.50 & 18.68 & $27.27 \%$ & -0.95 \\
\hline
\end{tabular}

Table 2:- Same as table 1 but honey-thick

\begin{tabular}{|l|l|l|l|l|l|}
\hline Honey-Thick Liquids Statistically Compared to Varibar Thin Honey Barium \\
\hline Type of Liquid & Trials & $\begin{array}{l}\text { Averaged } \\
\text { Viscosity } \\
(\mathrm{cP})\end{array}$ & $\begin{array}{l}\text { STD } \\
(\mathrm{cP})\end{array}$ & $\begin{array}{l}\text { Percentage } \\
\text { of Variance } \\
\text { (STD/ }\end{array}$ & $\begin{array}{l}\text { Correlation } \\
\text { Coefficient }\end{array}$ \\
\hline
\end{tabular}




\begin{tabular}{|c|c|c|c|c|c|}
\hline & & & & $\begin{array}{l}\text { Averaged } \\
\text { Viscosity) } \\
\end{array}$ & \\
\hline Varibar Thin Honey Barium & 10 & 3258.00 & 32.15 & $0.99 \%$ & \\
\hline \multicolumn{6}{|l|}{ Prethickened } \\
\hline GFS Lemon Water (Room Temperature) & 10 & 972.00 & 5.08 & $0.52 \%$ & 0.88 \\
\hline GFS Apple Juice (Room Temperature) & 10 & 1158.00 & 21.62 & $1.87 \%$ & 0.93 \\
\hline Thick-It Apple Juice (Room Temperature) & 10 & 714.40 & 0.95 & $0.13 \%$ & 0.62 \\
\hline Thick-It Water (Room Temperature) & 10 & 245.45 & 0.60 & $0.24 \%$ & 0.79 \\
\hline $\begin{array}{l}\begin{array}{l}\text { Hormel Thick \& } \\
\text { Temperature) }\end{array} \\
\end{array}$ & 10 & 1836.00 & 14.40 & $0.78 \%$ & 0.77 \\
\hline $\begin{array}{llllll}\text { Hormel Thick \& } & \text { Easy } & \text { Apple } & \text { Juice } & \text { (Room } \\
\text { Temperature) }\end{array}$ & 10 & 2120.00 & 14.40 & $0.68 \%$ & -0.56 \\
\hline $\begin{array}{l}\text { Hormel Thick \& Easy HydroLyte Water (Room } \\
\text { Temperature) }\end{array}$ & 10 & 1672.00 & 16.08 & $0.96 \%$ & 0.94 \\
\hline GFS Lemon Water (Cold) & 10 & 950.00 & 69.04 & $7.27 \%$ & 0.97 \\
\hline GFS Apple Juice (Cold) & 10 & 2126.00 & 65.75 & $3.09 \%$ & 0.83 \\
\hline Thick-It Apple Juice (Cold) & 10 & 750.80 & 2.70 & $0.36 \%$ & 0.95 \\
\hline Thick-It Water (Cold) & 10 & 194.60 & 1.09 & $0.56 \%$ & 0.93 \\
\hline Hormel Thick \& Easy Orange Juice (Cold) & 10 & 2002.00 & 39.67 & $1.98 \%$ & 0.16 \\
\hline Hormel Thick \& Easy Milk (Cold) & 10 & 2104.00 & 180.70 & $8.59 \%$ & 0.96 \\
\hline Hormel Thick \& Easy Apple Juice (Cold) & 10 & 3256.00 & 219.52 & $6.74 \%$ & 0.94 \\
\hline Hormel Thick \& Easy HydroLyte Water (Cold) & 10 & 2416.00 & 160.45 & $6.64 \%$ & 0.95 \\
\hline \multicolumn{6}{|l|}{ Gum-Based Thickeners } \\
\hline SimplyThick Water (Room Temperature) & 10 & 441.20 & 6.22 & $1.41 \%$ & -0.95 \\
\hline Thik \& Clear Water (Room Temperature) & 10 & 2314.00 & 13.62 & $0.59 \%$ & -0.54 \\
\hline Thicken Up Clear Water (Room Temperature) & 10 & 894.00 & 10.74 & $1.20 \%$ & -0.59 \\
\hline SimplyThick Water (Cold) & 10 & 451.20 & 4.71 & $1.04 \%$ & -0.65 \\
\hline Thik \& Clear Water (Cold) & 10 & 1786.00 & 231.70 & $12.97 \%$ & 0.91 \\
\hline Thicken Up Clear Water (Cold) & 10 & 1620.00 & 31.89 & $1.97 \%$ & -0.79 \\
\hline SimplyThick Coffee & 10 & 79.20 & 13.64 & $17.22 \%$ & -0.59 \\
\hline \multicolumn{6}{|l|}{ Starch-Based Thickeners } \\
\hline Thick \& Easy Water (Room Temperature) & 10 & 554.00 & 77.91 & $14.06 \%$ & -0.95 \\
\hline Thick-It Water (Room Temperature) & 10 & 662.00 & 137.81 & $20.82 \%$ & -0.56 \\
\hline Thick-It Water (Cold) & 10 & 558.00 & 71.13 & $12.75 \%$ & -0.46 \\
\hline Thick \& Easy Water (Cold) & 10 & 644.00 & 71.69 & $11.13 \%$ & -0.89 \\
\hline Thick-It Coffee & 10 & 139.20 & 45.87 & $32.95 \%$ & -0.95 \\
\hline
\end{tabular}

Table 3:- Minimum and maximum viscosity recorded during testing

\begin{tabular}{|l|l|l|l|}
\hline Minimum and Maximum Viscosity of Nectar-Thick Liquids \\
\hline Type of Liquid & $\begin{array}{l}\text { Minimum } \\
\text { Viscosity } \\
(\mathrm{cP})\end{array}$ & $\begin{array}{l}\text { Maximum } \\
\text { Viscosity } \\
\text { (cP) }\end{array}$ & $\begin{array}{l}\text { Averaged } \\
\text { Viscosity } \\
\text { (cP) }\end{array}$ \\
\hline Varibar Nectar Barium & 87.41 & 89.64 & 88.53 \\
\hline Prethickened & 458.40 & 484.80 & 471.60 \\
\hline GFS Lemon Water (Room Temperature) & 449.60 & 512.00 & 480.80 \\
\hline GFS Apple Juice (Room Temperature) & 389.60 & 438.40 & 414.00 \\
\hline Thick-It Apple Juice (Room Temperature) & 136.10 & 138.90 & 137.50 \\
\hline Thick-It Water (Room Temperature) & 131.00 & 143.10 & 137.05 \\
\hline Hormel Thick \& Easy Orange Juice (Room Temperature) & 918.80 & 965.60 & 942.20 \\
\hline Hormel Thick \& Easy Apple Juice (Room Temperature) & 368.80 & 396.90 & 382.85 \\
\hline Hormel Thick \& Easy HydroLyte Water (Room Temperature) & 790.6 & 879.9 & 835.25 \\
\hline GFS Lemon Water (Cold) & 200.8 & 224.8 & 212.80 \\
\hline GFS Apple Juice (Cold) & & & \\
\hline
\end{tabular}




\begin{tabular}{|c|c|c|c|}
\hline Thick-It Apple Juice (Cold) & 428.8 & 435.2 & 432.00 \\
\hline Thick-It Water (Cold) & 141.6 & 143.9 & 142.75 \\
\hline Hormel Thick \& Easy Orange Juice (Cold) & 175.4 & 195.4 & 185.40 \\
\hline Hormel Thick \& Easy Milk (Cold) & 1724 & 2044 & 1884.00 \\
\hline Hormel Thick \& Easy Apple Juice (Cold) & 885.9 & 1147 & 1016.45 \\
\hline Hormel Thick \& Easy HydroLyte Water (Cold) & 914.1 & 1128 & 1021.05 \\
\hline \multicolumn{4}{|l|}{ Gum-Based Thickeners } \\
\hline SimplyThick Water (Room Temperature) & 158.40 & 180.00 & 169.20 \\
\hline Thik \& Clear Water (Room Temperature) & 465.60 & 478.40 & 472.00 \\
\hline Thicken Up Clear Water (Room Temperature) & 297.60 & 358.40 & 328.00 \\
\hline SimplyThick Water (Cold) & 218.40 & 232.80 & 225.60 \\
\hline Thik \& Clear Water (Cold) & 560.00 & 599.00 & 579.50 \\
\hline Thicken Up Clear Water (Cold) & 300.80 & 357.60 & 329.20 \\
\hline SimplyThick Coffee & 89 & 122.2 & 105.60 \\
\hline \multicolumn{4}{|l|}{ Starch-Based Thickeners } \\
\hline Thick \& Easy Water (Room Temperature) & 62.40 & 115.20 & 88.80 \\
\hline Thick-It Water (Room Temperature) & 108.80 & 164.00 & 136.40 \\
\hline Thick-It Water (Cold) & 232.00 & 333.60 & 282.80 \\
\hline Thick \& Easy Water (Cold) & 93.60 & 127.20 & 110.40 \\
\hline Thick-It Coffee & 38.2 & 98.8 & 68.50 \\
\hline
\end{tabular}

Table 4:- Same as Table 3 but honey-thick

\begin{tabular}{|l|l|l|l|}
\hline Minimum and Maximum Viscosity of Honey-Thick Liquids \\
\hline Type of Liquid & $\begin{array}{l}\text { Minimum } \\
\text { Viscosity } \\
(\mathrm{cP})\end{array}$ & $\begin{array}{l}\text { Maximum } \\
\text { Viscosity } \\
(\mathrm{cP})\end{array}$ & $\begin{array}{l}\text { Averaged } \\
\text { Viscosity } \\
(\mathrm{cP})\end{array}$ \\
\hline Varibar Thin Honey Barium & 3468.00 & 3588.00 & 3258.00 \\
\hline Prethickened & 964.00 & 980.00 & 972.00 \\
\hline GFS Lemon Water (Room Temperature) & 1124.00 & 1192.00 & 1158.00 \\
\hline GFS Apple Juice (Room Temperature) & 712.80 & 716.00 & 714.40 \\
\hline Thick-It Apple Juice (Room Temperature) & 244.40 & 246.50 & 245.45 \\
\hline Thick-It Water (Room Temperature) & 1804.00 & 1868.00 & 1836.00 \\
\hline Hormel Thick \& Easy Orange Juice (Room Temperature) & 2096.00 & 2144.00 & 2120.00 \\
\hline Hormel Thick \& Easy Apple Juice (Room Temperature) & 1648.00 & 1696.00 & 1672.00 \\
\hline Hormel Thick \& Easy HydroLyte Water (Room Temperature) & 828.00 & 1072.00 & 950.00 \\
\hline GFS Lemon Water (Cold) & 2028.00 & 2224.00 & 2126.00 \\
\hline GFS Apple Juice (Cold) & 746.40 & 755.20 & 750.80 \\
\hline Thick-It Apple Juice (Cold) & 192.80 & 196.40 & 194.60 \\
\hline Thick-It Water (Cold) & 1952.00 & 2052.00 & 2002.00 \\
\hline Hormel Thick \& Easy Orange Juice (Cold) & 1792.00 & 2416.00 & 2104.00 \\
\hline Hormel Thick \& Easy Milk (Cold) & 2880.00 & 3632.00 & 3256.00 \\
\hline Hormel Thick \& Easy Apple Juice (Cold) & 2160.00 & 2672.00 & 2416.00 \\
\hline Hormel Thick \& Easy HydroLyte Water (Cold) & \multicolumn{3}{l|}{} \\
\hline Gum-Based Thickeners & 431.20 & 451.20 & 441.20 \\
\hline SimplyThick Water (Room Temperature) & 2292.00 & 2336.00 & 2314.00 \\
\hline Thik \& Clear Water (Room Temperature) & 876.00 & 912.00 & 894.00 \\
\hline Thicken Up Clear Water (Room Temperature) & 442.40 & 460.00 & 451.20 \\
\hline SimplyThick Water (Cold) & 1416.00 & 2156.00 & 1786.00 \\
\hline Thik \& Clear Water (Cold) & 1572.00 & 1668.00 & 1620.00 \\
\hline Thicken Up Clear Water (Cold) & 57.20 & 101.20 & 79.20 \\
\hline SimplyThick Coffee & \multicolumn{2}{l|}{} \\
\hline Starch-Based Thickeners & 424.00 & 684.00 & 554.00 \\
\hline Thick \& Easy Water (Room Temperature) & 424.00 & 900.00 & 662.00 \\
\hline Thick-It Water (Room Temperature) & \multicolumn{2}{l|}{} \\
\hline
\end{tabular}




\begin{tabular}{|l|l|l|l|}
\hline Thick-It Water (Cold) & 436.00 & 680.00 & 558.00 \\
\hline Thick \& Easy Water (Cold) & 536.00 & 752.00 & 644.00 \\
\hline Thick-It Coffee & 64.00 & 214.40 & 139.20 \\
\hline
\end{tabular}

\section{Nectar-Thick Gum-Based Thickeners Compared to Varibar Nectar Barium}

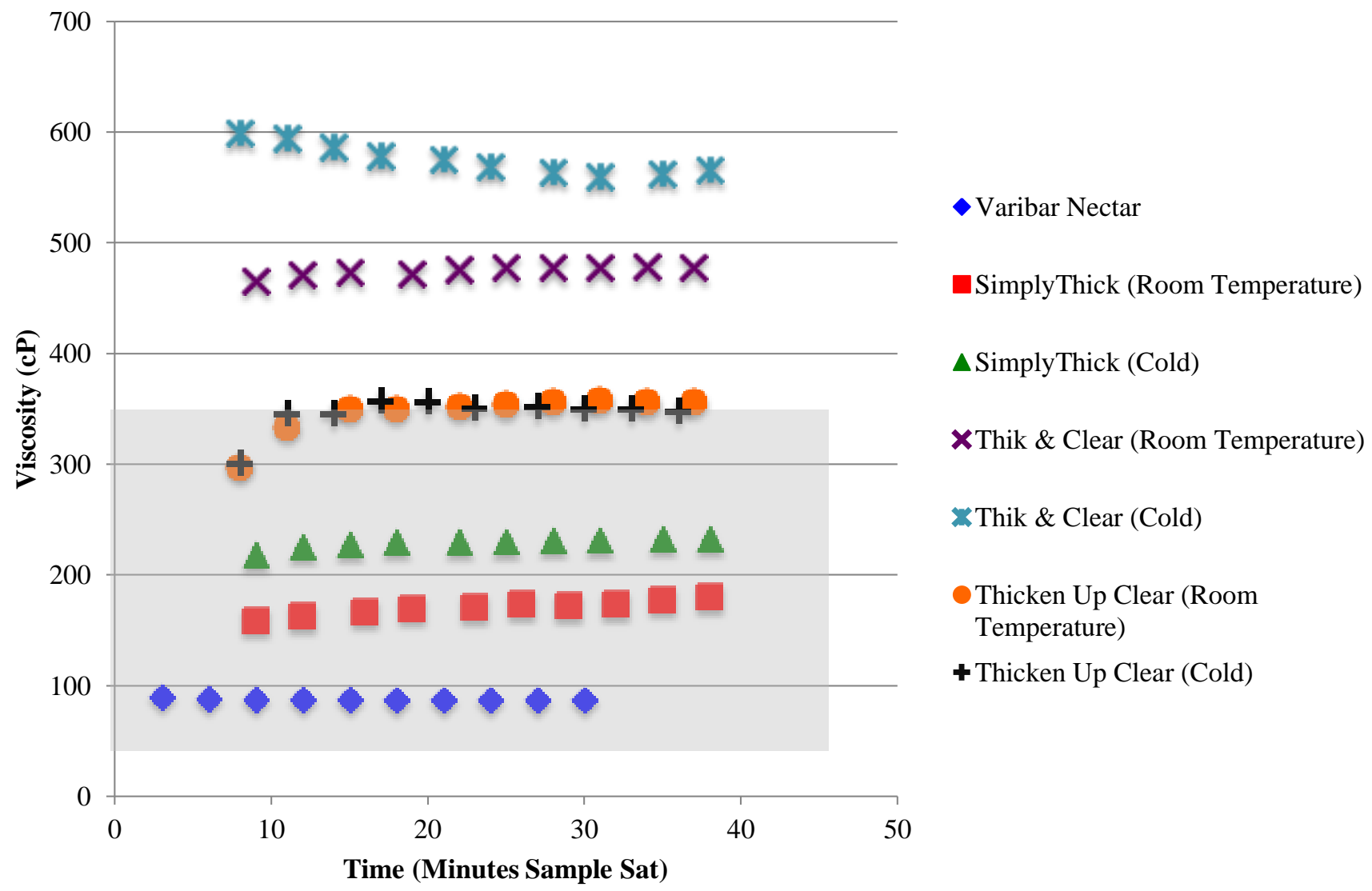

Fig. 1:- Nectar-thick gum-based thickeners were compared to Varibar Nectar Barium. The shaded region indicates NDD range for nectar-thick liquids 


\section{Nectar-Thick Starch-Based Thickeners Compared to Varibar Nectar Barium}

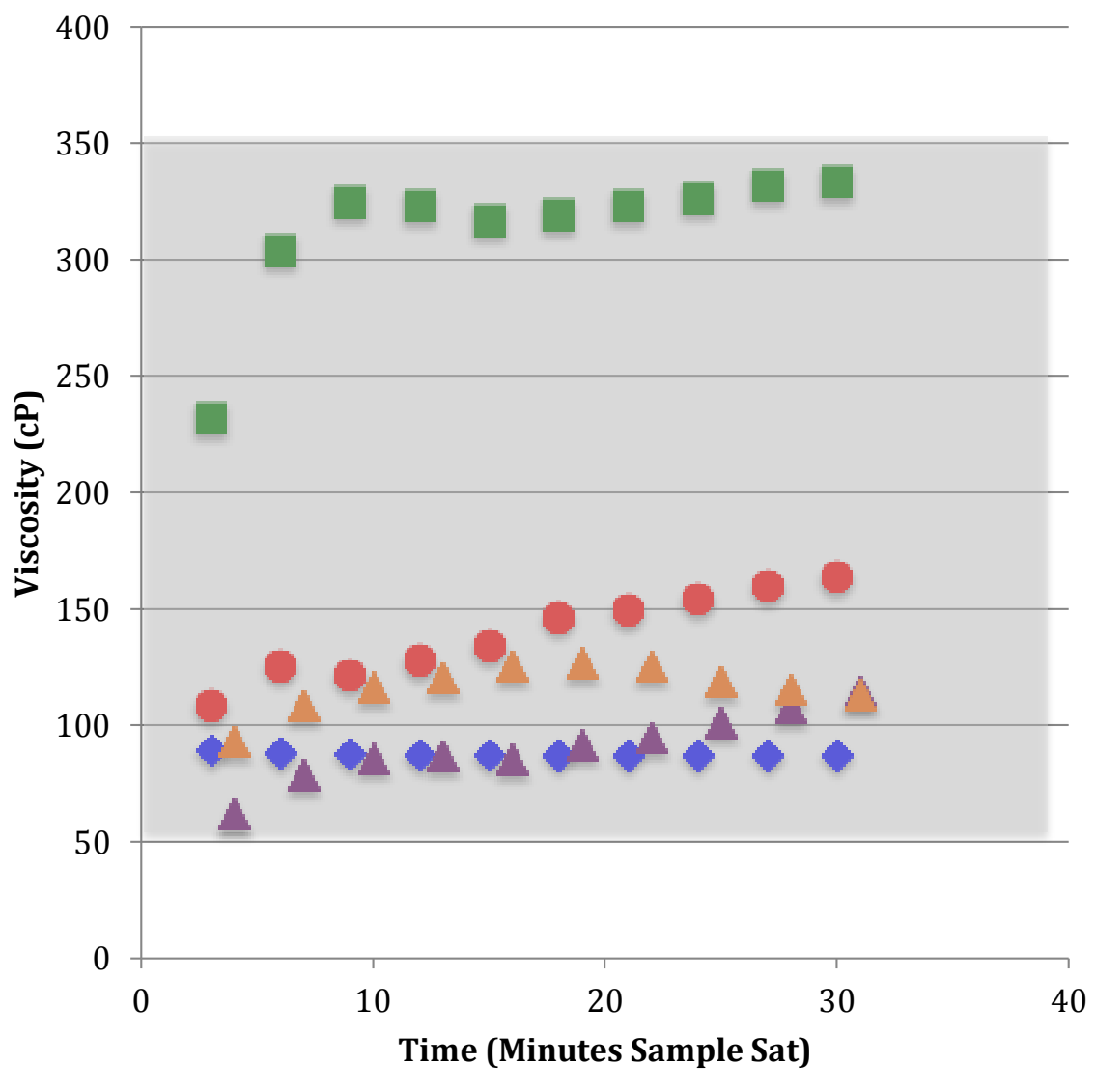

- Varibar Nectar

- Thick-It (Room Temperature)

- Thick-It (Cold)

$\Delta$ Thick \& Easy (Room Temperature)

$\triangle$ Thick \& Easy (Cold)

Fig. 2:- Same as Fig. 1 but with starch-based thickeners. 


\section{Nectar-Thick Prethickened Room Temperature Liquids \\ Compared to Varibar Nectar Barium}

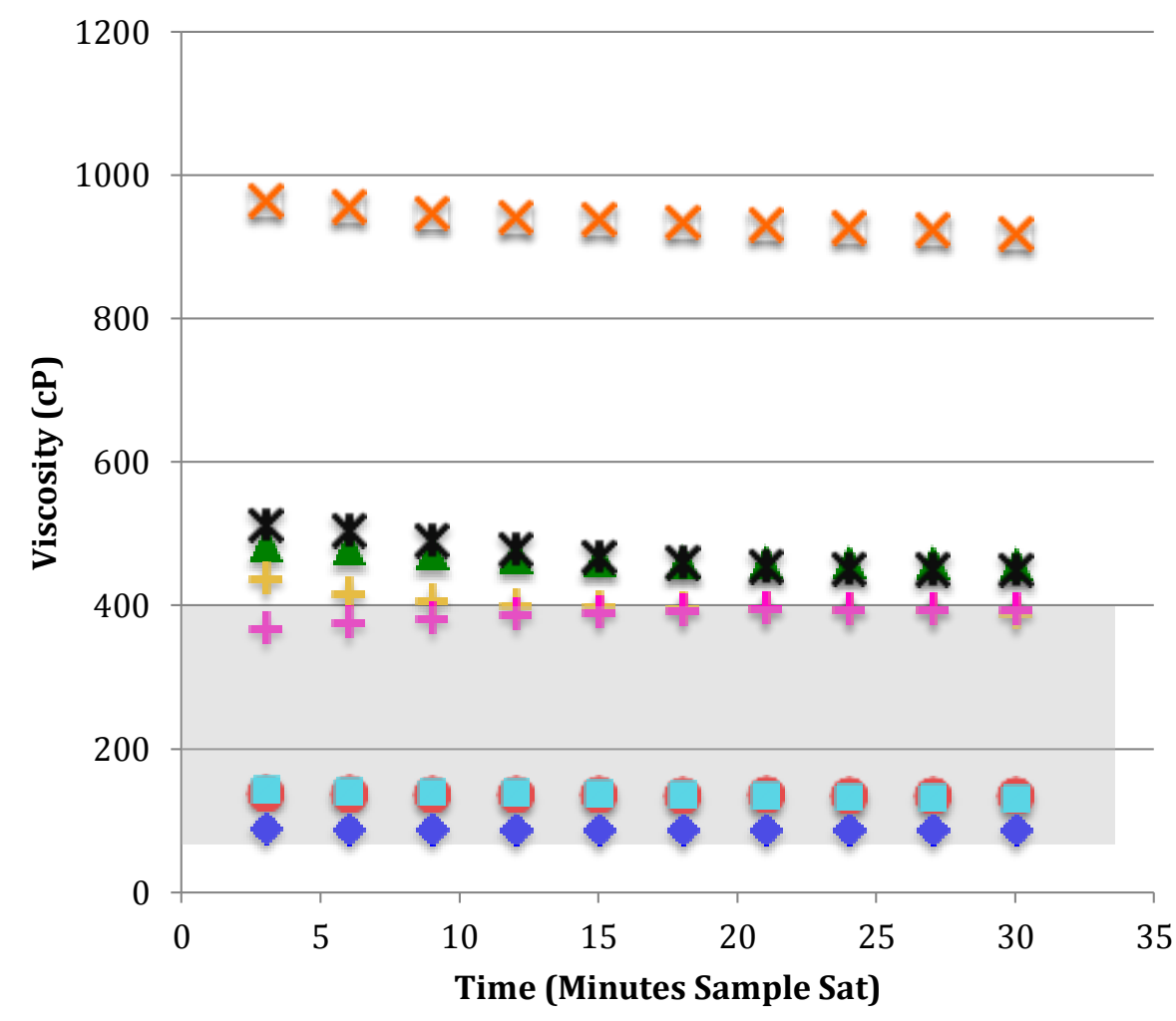

- Varibar Nectar

$\Delta$ GFS Lemon Water (Room Temperature)

× GFS Apple Juice (Room Temperature)

\# Thick-It Apple Juice (Room Temperature)

- Thick-It Water (Room Temperature)

Hormel Thick \& Easy Orange Juice (Room Temperature)

X Hormel Thick \& Easy Apple Juice (Room Temperature)

+ Hormel Thick \& Easy HydroLyte Water (Room Temperature)

Fig. 3:- Same as Fig. 2 but with prethickened room temperature liquids. 


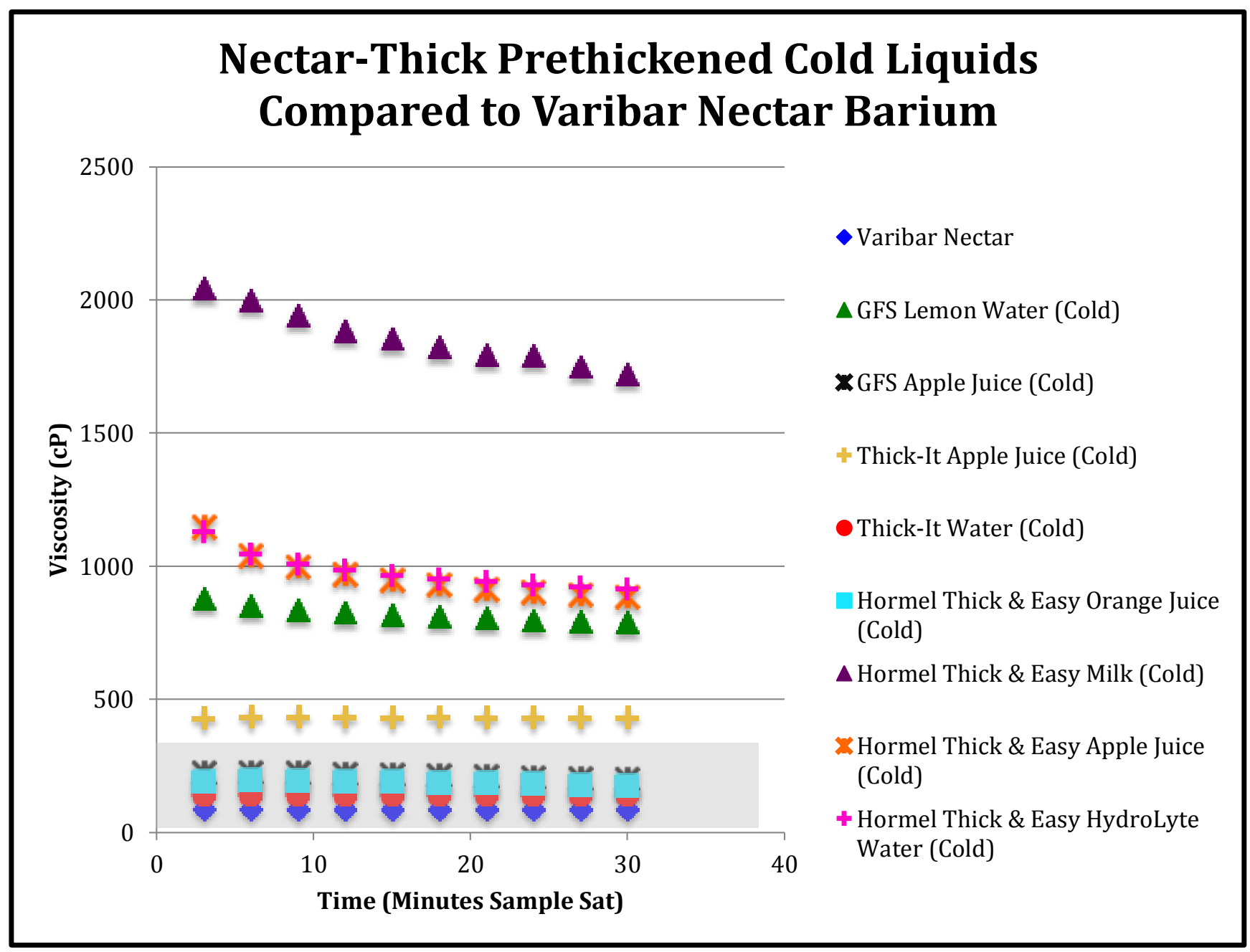

Fig. 4:- Same as Fig. 3 but cold 


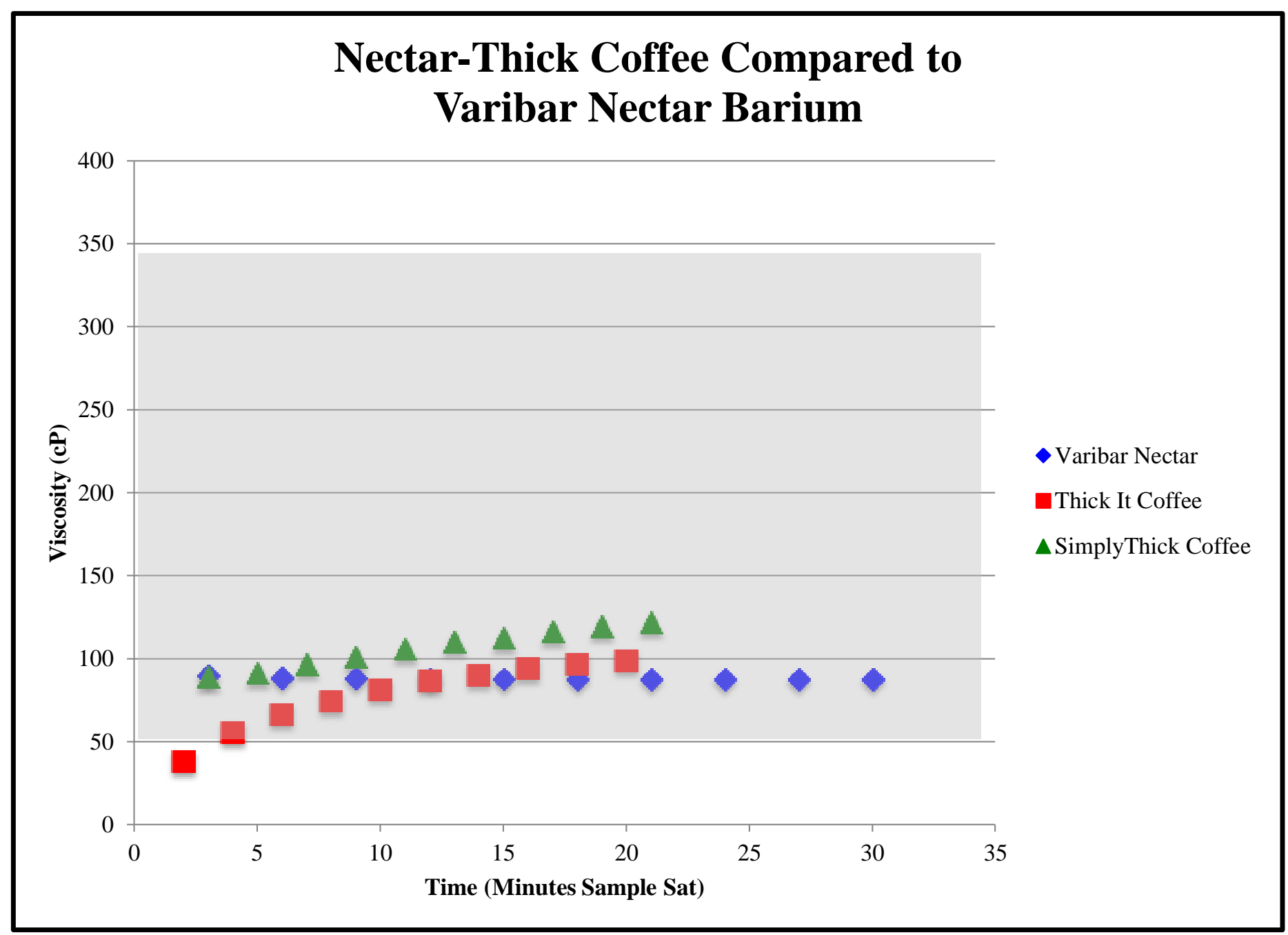

Fig. 5:- Same as Fig. 4 but with coffee 


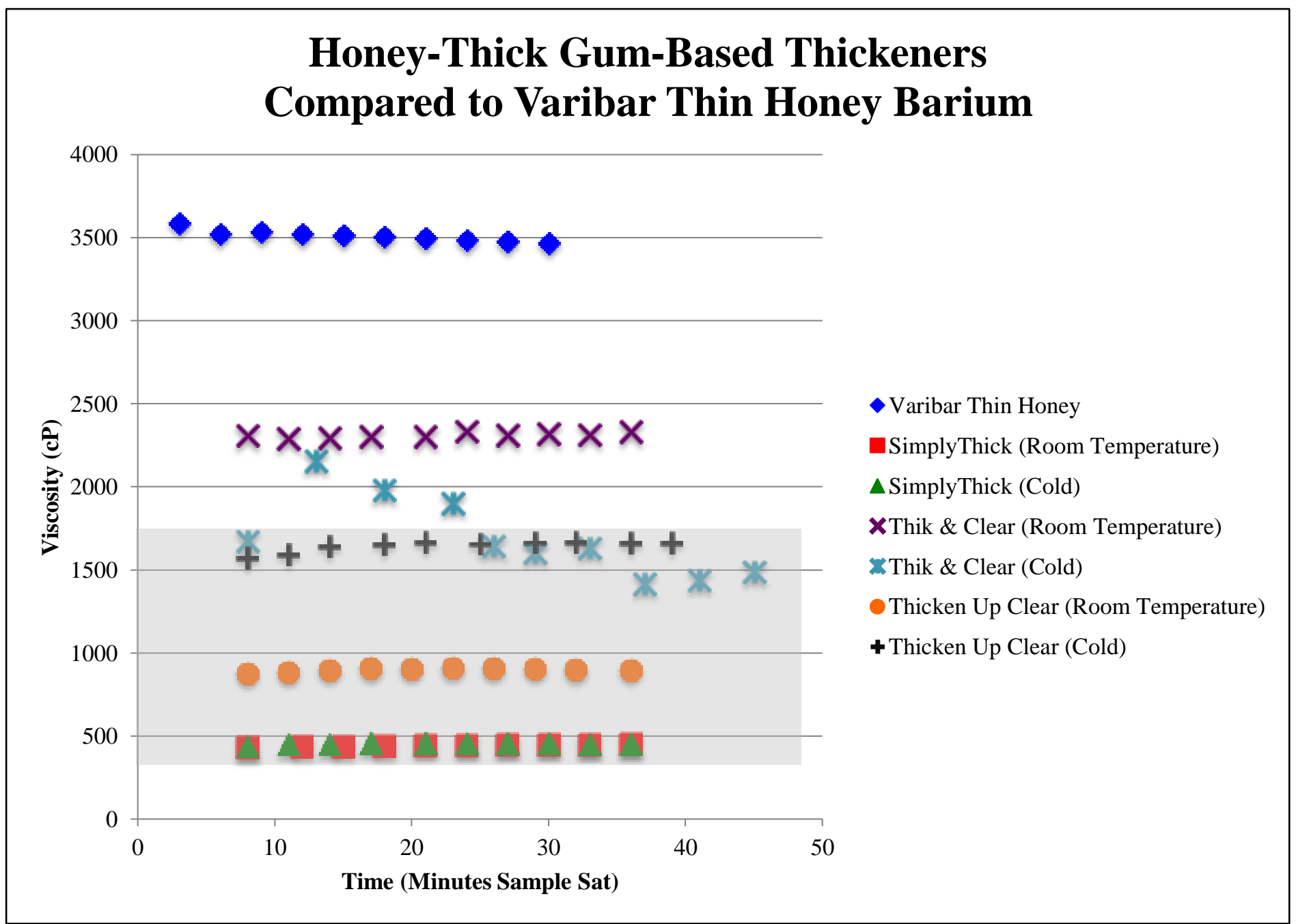

Fig. 6:- Same as Fig. 1 but honey-thick 


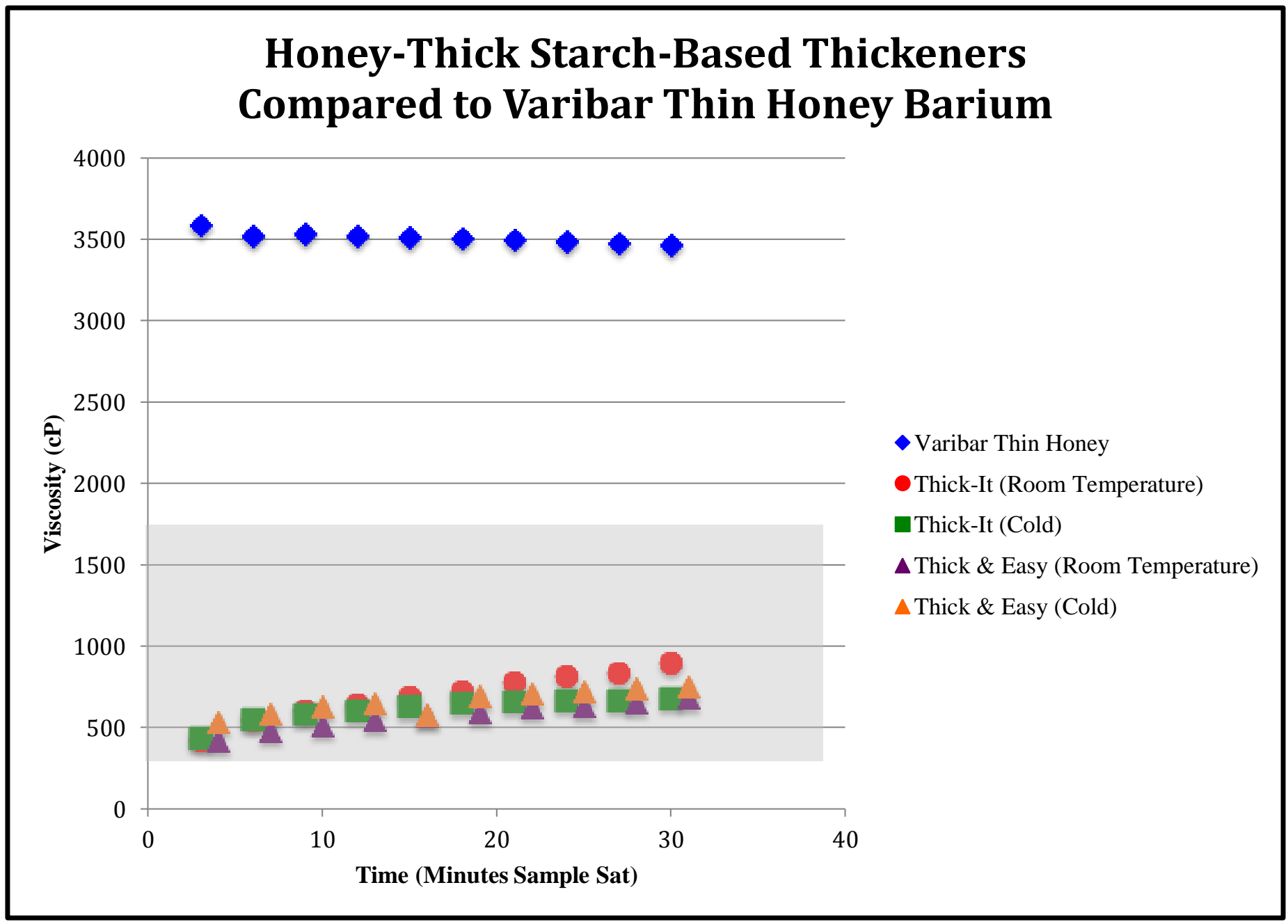

Fig. 7:- Same as Fig. 2 but honey-thick 


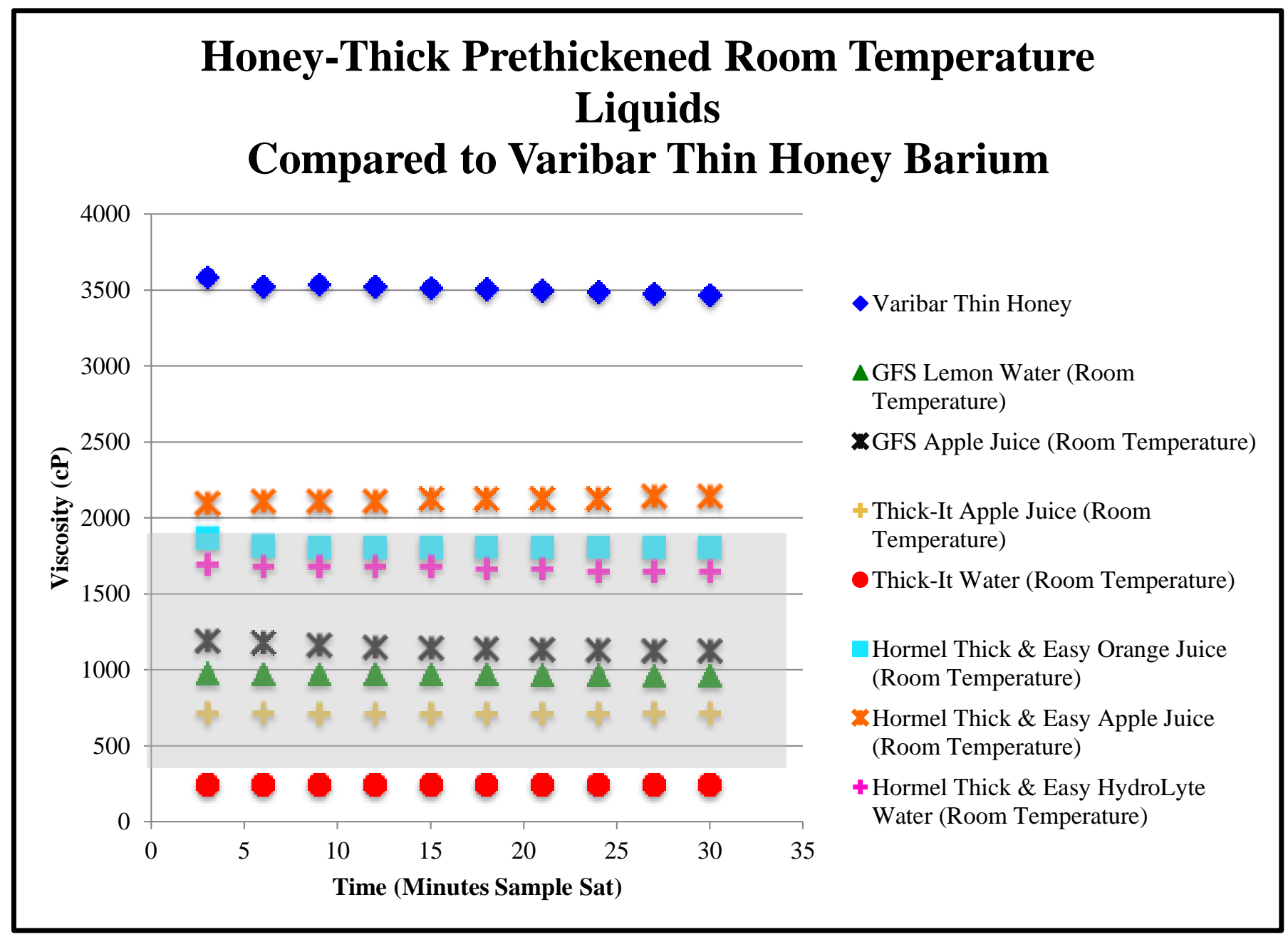

Fig. 8:- Same as Fig. 3 but honey-thick 


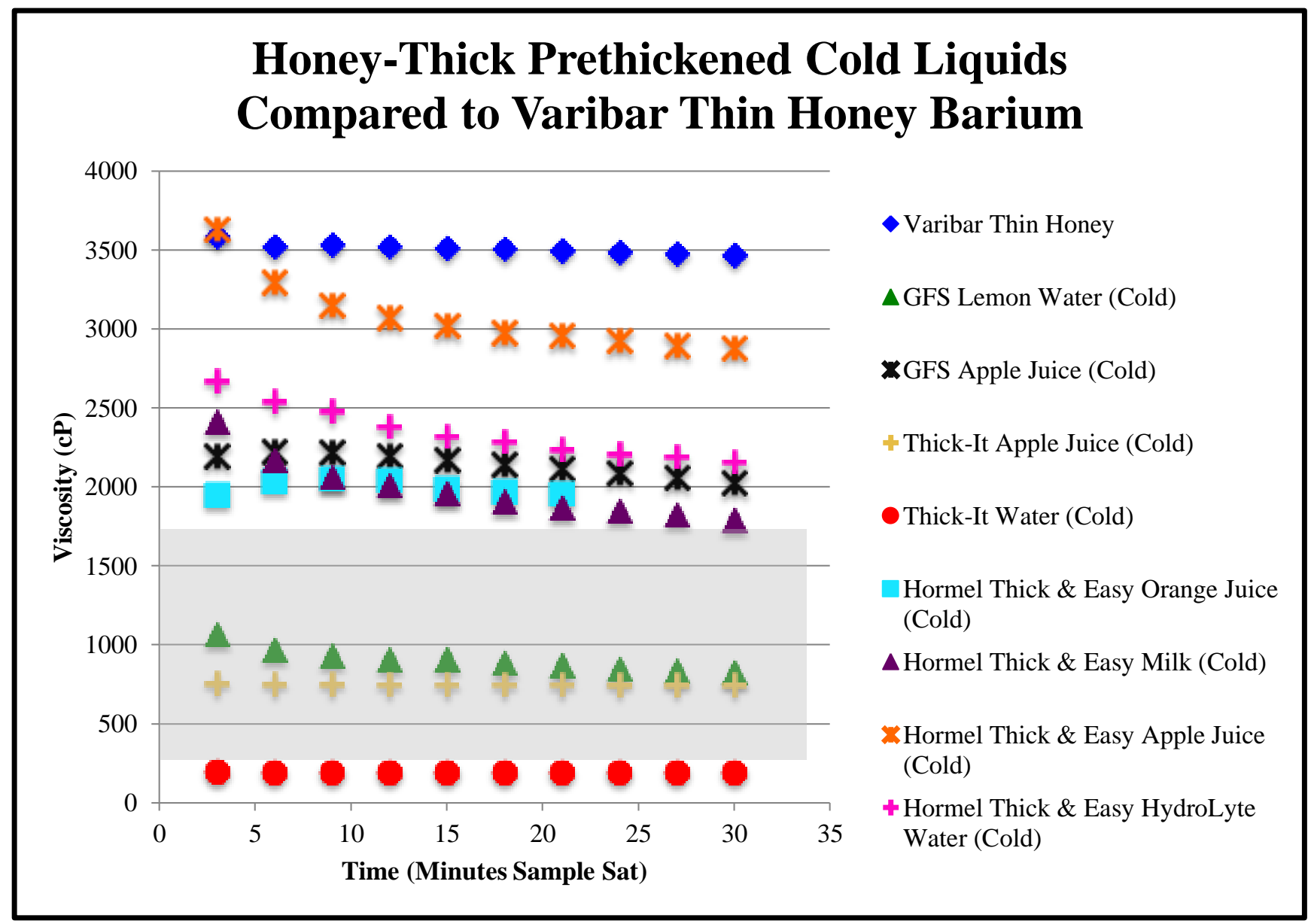

Fig. 9:- Same as Fig. 4 but honey-thick 


\section{Honey-Thick Coffee Compared to Varibar Thin Honey Barium}

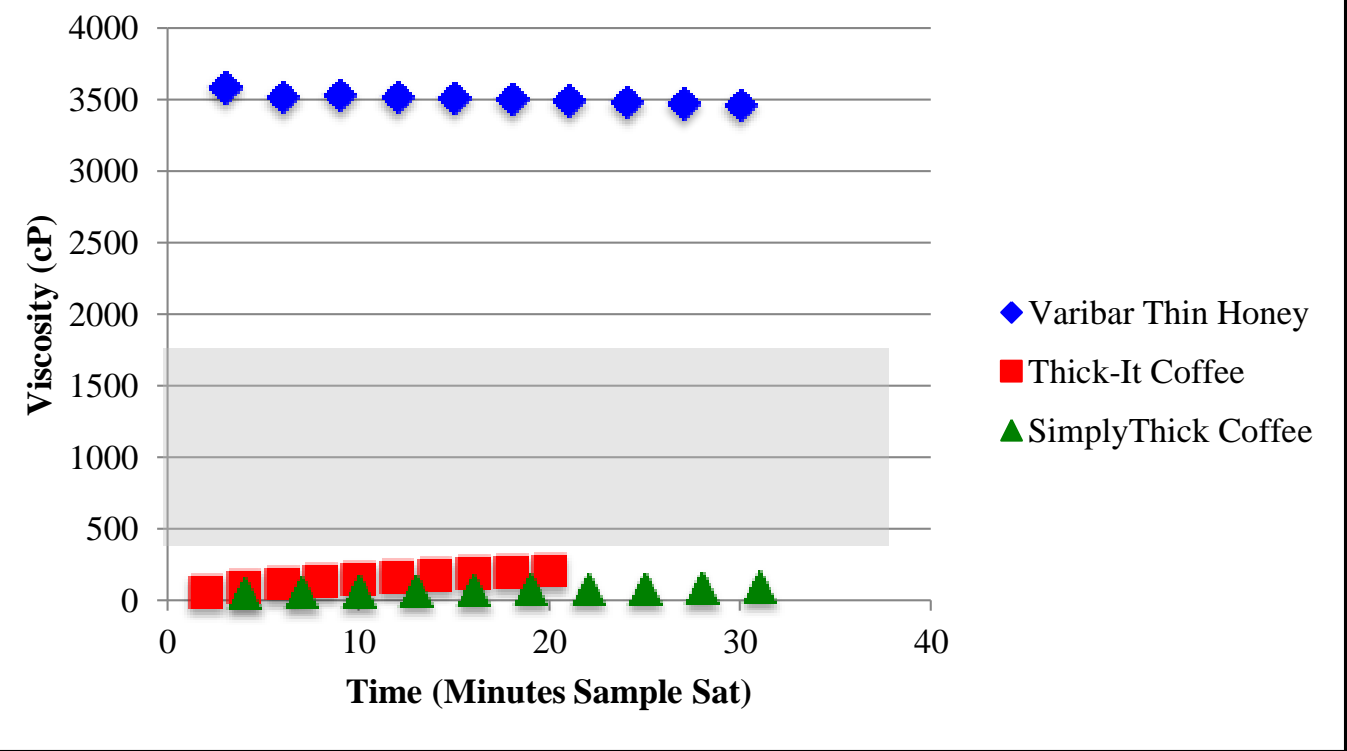

Fig. 10:- Same as Fig. 5 but honey-thick

\section{References:-}

1. Mertz Garcia, J., Chambers, IV, E., Clark, M., Helverson, J., \& Matta, Z. (2010). Quality of care issues for dysphagia: Modifications involving oral fluids. Journal of Clinical Nursing, 19(11/12), 1618-1624.

2. Cichero, J.A.Y., Steele, C., Duivestein, J., Clave , P., Chen, J., Kayashita, J., Dantas, R., Lecko, C., Speyer, R., Lam, P., \& Murray, J. (2013). The need for international terminology and definitions for texture-modified foods and thickened liquids used in dysphagia management: Foundations of a global initiative. Current Physical Medicine and Rehabilitation Reports, 1(4), 280-291.

3. Lancaster, J. (2015). Dysphagia: Its nature, assessment and management. British Journal of Community Nursing, 20, S28-S32.

4. Holland, G., Jayasekeran, V., Pendleton, N., Horan, M., Jones, M., \& Hamdy, S. (2011). Prevalence and symptom profiling of oropharyngeal dysphagia in a community dwelling of an elderly population: A selfreporting questionnaire survey. Diseases of the Esophagus, 24(7), 476-480.

5. McCullough, G., Pelletier, C., \& Steele, C. National dysphagia diet: What to swallow? ASHA Leader 2003;16:27-9.

6. Mertz Garcia, J., Chambers, IV, E., \& Molander, M. (2005). Thickened liquids: Practice patterns of speechlanguage pathologists. American Journal of Speech-Language Pathology, 14, 4-13.

7. Mertz Garcia, J. \& Chambers, IV, E. (2006). Insights into practice patterns for thickened liquids. Swallowing and Swallowing Disorders 14-18.

8. Davis, E., Hartney, C., LaGorio, L., Gustashaw, K., Keim, K., \& Sowa, D. (2016) The national dysphagia diet perceptions and practice patterns among registered dietitian-nutritionists and speech-language pathologists. Journal of the Academy of Nutrition and Dietetics, 116(90), A96.

9. Heiss, C.J., Goldberg, L., \& Dzarnoski, M. (2010). Registered dietitians and speech-language pathologists: An important partnership in dysphagia management. Journal of the American Dietetic Association, 110(9), 12901293.

10. Payne, C., Methven, L., Fairfield, C., Gosney, M., Bell, A.E. (2011). Variability of starch-based thickened drinks for patients with dysphagia in the hospital setting. Journal of Texture Studies, 43, 95-105.

11. Glassburn, D.L., Deem, J.F. (1998). Thickener viscosity in dysphagia management: Variability among speechlanguage pathologists. Dysphagia, 13, 218-222. 